\title{
Cadeias agroalimentares curtas e o mercado de alimentação escolar na rede municipal de ljuí, RS
}

\author{
Short agri-food chains and the school food market in the municipal network of \\ Ijuí, RS
}

\section{Les chaînes agroalimentaires courtes et le marché de l'alimentation scolaire dans le réseau municipal d'ljuí, RS}

\section{Cadenas agroalimentarias cortas y el mercado de alimentación escolar en la red municipal de ljuí, RS}

\author{
Indaia Dias Lopes ${ }^{1}$ \\ David Basso ${ }^{2}$ \\ Argemiro Luís Brum²
}

\begin{abstract}
Recebido em 29/11/2017; revisado e aprovado em 03/04/2018; aceito em 13/04/2018
\end{abstract}
DOI: http://dx.doi.org/10.20435/inter.v0i0.1773

\begin{abstract}
Resumo: Este artigo tem como objetivo avaliar o funcionamento do mercado gerado pelo Programa Nacional de Alimentação Escolar (PNAE) na rede escolar municipal de ljuí, RS, sob o enfoque das cadeias agroalimentares curtas. Trata-se de uma pesquisa explicativa, com abordagem qualitativa dos dados. No município de ljuí foram criadas parcerias entre os diferentes atores sociais envolvidos com o PNAE de modo a organizar os agricultores familiares locais para participarem deste mercado.
\end{abstract}

Palavras-chave: cadeias agroalimentares curtas; alimentação escolar; agricultura familiar.

Abstract: This article aims to evaluate the functioning of the market generated by the National School Feeding Program (PNAE) in the municipal school network of Ijuí, RS, under the focus of the short agri-food chains. It is an explanatory research, with qualitative approach of the data. In the municipality of ljuí, partnerships were created between the different social actors involved with the PNAE in order to organize local family farmers to participate in this market.

Keywords: short agri-food chain; school feeding; family farming.

Résumé: Cet article vise à évaluer le fonctionnement du marché généré par le Programme National d'Alimentation Scolaire (PNAE) dans le réseau scolaire municipal d'ljuí, RS, dans le cadre des courtes chaînes agroalimentaires. C'est une recherche explicative, avec une approche qualitative des données. Dans la municipalité d'Ijuí, des partenariats ont été créés entre les différents acteurs sociaux impliqués dans le PNAE afin d'organiser la participation des agriculteurs familiaux locaux à ce marché.

Mots-clés: chaînes agroalimentaires courtes; I'alimentation scolaire; I'agriculture familiale.

Resumen: Este artículo tiene como objetivo evaluar el funcionamiento del mercado generado por el Programa Nacional de Alimentación Escolar (PNAE) en la red escolar municipal de ljuí (RS), bajo el enfoque de las cadenas agroalimentarias cortas. Se trata de una investigación explicativa, con abordaje cualitativo de los datos. En el municipio de ljuí se crearon alianzas entre los diferentes actores sociales involucrados con el PNAE para organizar a los agricultores familiares locales para participar en este mercado.

Palabras clave: cadenas agroalimentarias cortas; alimentación escolar; agricultura familiar.

\footnotetext{
${ }^{1}$ Universidade de Passo Fundo (UPF), Passo Fundo, Rio Grande do Sul, Brasil.

${ }^{2}$ Universidade Regional do Noroeste do Estado do Rio Grande do Sul (Unijuí), ljuí, Rio Grande do Sul, Brasil.
} 


\section{INTRODUÇÃO}

As sociedades buscam alternativas de vida saudáveis e sustentáveis. Nesse sentido, a produção, o processamento, a distribuição e o consumo dos alimentos tornaram-se assuntos importantes na agenda dos governos dos diferentes países (ORGANIZACIÓN DE LÁS NACIONES UNIDAS PARA LA AGRICULTURA Y LA ALIMENTACIÓN [FAO], 2011). Os alimentos são elementos fundamentais nos modelos de desenvolvimento socioeconômico sustentável regulado tanto pelo Estado como pelo mercado (TRICHES, 2015).

Diversos autores (MORGAN; SONINNO, 2010; TRICHES; SCHNEIDER, 2010; TRICHES, 2015) vêm direcionando seus estudos no intuito de compreender melhor os benefícios da aproximação entre o mercado da alimentação escolar e produtos com origem na agricultura familiar local.

No tocante às políticas de alimentação voltadas para o público escolar, o Brasil possui o Programa Nacional de Alimentação Escolar (PNAE), sendo esse programa de fundamental importância para o desenvolvimento local. Até o ano de 2009, as compras públicas para o PNAE eram regidas pela Lei n. 8666/1993, considerando o menor preço, por meio de licitações públicas. Os requisitos burocráticos exigidos dos fornecedores para se habilitarem às licitações (TRICHES; BACCARIN, 2016) constituíam-se em impeditivos à participação de agricultores familiares.

Ao implementar a Lei n. 11.947/2009, o governo brasileiro introduziu uma inovação buscando aliar as aquisições de produtos para a alimentação escolar ao fortalecimento da agricultura familiar local, determinando que um percentual mínimo de 30\% dos recursos repassados pelo Fundo Nacional de Desenvolvimento da Educação (FNDE) para compras destinadas à alimentação escolar fosse destinado à aquisição de produtos de agricultores familiares (FNDE, s.d.). Essa legislação recomenda que seja priorizada a compra dos agricultores familiares do município executor do PNAE. Caso isso não seja possível, deve-se adotar a seguinte ordem: compra de agricultores da região, do território rural, do Estado e, por fim, de outros Estados (TRICHES; BACCARIN, 2016).

Segundo Triches (2015), a mudança na legislação em 2009, tornando obrigatória a inclusão do agricultor familiar como fornecedor da alimentação escolar, beneficiou os alunos que recebem esses alimentos, os agricultores e também o meio ambiente. Além disso, vários municípios vêm utilizando mais de $30 \%$ dos seus recursos em alimentação escolar para aquisição de produtos com origem da agricultura familiar. Para a referida autora, o Brasil foi um dos primeiros países a estabelecer políticas de alimentação escolar transformando o PNAE em uma estratégia de desenvolvimento sustentável.

Como destacado por Triches e Schneider (2010, p. 944), a proximidade entre os atores envolvidos no processo de aquisição de produtos para a alimentação escolar "cria relações de confiança e mútuo respeito e proporciona conhecimentos, concertamentos e benefícios para ambas as partes". Essas novas relações, segundo os autores, trazem resultados positivos para todos os sujeitos envolvidos, modificando os hábitos alimentares dos alunos pelo consumo de alimentos mais saudáveis, criando oportunidades para a agricultura familiar e estimulando práticas de produção menos danosas em termos ambientais.

Froehlich (2010) igualmente destaca que as características envolvidas no processo de aquisição de produtos diretamente de agricultores familiares locais potencializam vantagens para todos os envolvidos nesse processo, além de aliar Segurança Alimentar e Nutricional (SAN) e desenvolvimento local. 
Na operacionalização do PNAE, os gestores têm se deparado com muitos desafios, relacionados principalmente às normas sanitárias, para garantir a participação de agricultores familiares no programa. Esses desafios, segundo Triches e Baccarin (2016), ficam mais evidentes no caso da aquisição de produtos de origem animal, como carne e leite e seus derivados, os quais têm a obrigatoriedade de serem processados em laticínios e frigoríficos, sendo que estes, geralmente, possuem plantas de grande porte.

Diante do exposto, este artigo está inserido no contexto da reaproximação entre produtores e consumidores, conhecido na literatura como cadeias curtas de abastecimento alimentar, tendo como objetivo avaliar o impacto do mercado gerado pelo PNAE para a rede escolar municipal de ljuí, RS, após a implementação da Lei n. 11.947/2009.

Além desta introdução, o trabalho está dividido em quatro partes, a saber: os procedimentos metodológicos utilizados no estudo que deu origem a este artigo; as questões teóricas que norteiam as cadeias curtas de abastecimento alimentar e o mercado de alimentação escolar; a caracterização do município de ljuí, o mercado da alimentação escolar no município e o impacto da Lei n. 11.947/2009 para o mercado de alimentação escolar municipal na perspectiva das cadeias curtas de abastecimento alimentar e, por fim, as considerações finais, destacando os desafios enfrentados pelos gestores do programa no município.

\section{DELINEAMENTOS METODOLÓGICOS}

Para desenvolver este trabalho, optou-se por uma pesquisa de caráter qualitativo, a qual buscou conteúdos explicativos especialmente em dados primários, ainda que se abastecendo de dados secundários para subsidiar qualitativamente a análise. Quanto ao nível do estudo, trata-se de uma pesquisa explicativa que, segundo Gil (2016), procura identificar quais elementos auxiliam para os fenômenos acontecerem.

Nesta pesquisa, investiga-se quais os impactos do mercado gerado pelo PNAE para a rede escolar municipal de ljuí após a implementação da Lei n. 11.947/2009, sob o enfoque das cadeias agroalimentares curtas. Com a implementação da referida lei, em seu artigo 14, ficou determinado que, no mínimo, 30\% dos recursos repassados pelo FNDE aos Estados e municípios devem ser investidos em produtos de origem na agricultura familiar.

Foram selecionados como sujeitos da pesquisa os servidores que participam do processo de execução e gestão do PNAE no município, além da diretora de uma escola municipal. Para tanto, foram realizadas três entrevistas abertas, orientadas por um roteiro elaborado anteriormente, dirigidas aos seguintes agentes: o secretário de educação do município; a nutricionista responsável pela coordenação do programa de alimentação escolar na rede municipal de ljuí; e a diretora de uma escola municipal. Vale lembrar que o PNAE, no âmbito das escolas municipais de Ijuí, possui uma gestão municipalizada, centralizada na Coordenadoria de Nutrição Escolar, a qual realiza as compras para todas as escolas municipais, de modo que o que acontece em uma escola se reproduz nas demais escolas. As entrevistas foram gravadas com autorização dos depoentes e posteriormente foram transcritas com o uso da ferramenta Microsoft Word 2007 e analisadas em confronto com a literatura. Além das entrevistas, foi utilizada a técnica de observação não participante.

Os dados foram analisados com base na metodologia de Análise de Situações de Desenvolvimento (ASD), a qual prioriza o contato direto com a realidade, de modo que o pes- 
quisador compreenda o que se propõe a estudar, por meio de observações diretas e entrevistas abertas, considerando que cada aspecto da realidade que se deseja estudar envolve níveis ou etapas particulares e procedimentos específicos (BASSO, 2012).

Nesse sentido, qualquer ASD deve levar em consideração alguns princípios metodológicos, como os destacados por Silva Neto (2007, p. 36):

- efetuar as análises a partir dos fenômenos mais gerais para os particulares, por meio de uma abordagem sistêmica em vários níveis;

- analisar cada nível da realidade especificamente, efetuando uma síntese dos níveis de análise mais abrangentes, antes de passar a analisar os níveis mais específicos;

- priorizar a explicação em detrimento da descrição, privilegiando o enfoque histórico;

- estar atento à heterogeneidade da realidade, evitando interpretações por demais generalizantes que dificultam a elucidação de processos de diferenciação.

Os estudos conduzidos a partir dos princípios enunciados acima, portanto, devem ser realizados levando-se em conta uma rigorosa hierarquização das análises considerando-se sua abrangência, iniciando pelos aspectos mais gerais da realidade sob observação, passando-se aos mais específicos somente após ter sido feita uma síntese que permita identificar as variáveis mais pertinentes a serem analisadas, ou as questões mais importantes que precisam ser respondidas no nível imediatamente inferior (SILVA NETO, 2007).

No caso deste estudo, cada nível foi analisado, separado e progressivamente, procurando responder aos questionamentos e com foco nas informações com maior poder de explicação. No primeiro nível, foi realizada uma caracterização do município estudado e sua rede escolar municipal. O segundo nível contemplou a realização das entrevistas com os informantes-chave na operacionalização do PNAE no âmbito local, buscando traçar um histórico da alimentação escolar em ljuí. O terceiro nível procurou identificar os impactos da Lei n. 11.947/2009 para os principais atores sociais envolvidos no Programa.

\section{AS CADEIAS AGROALIMENTARES CURTAS E A ALIMENTAÇÃO ESCOLAR: REFERENCIAL TEÓRICO}

As cadeias curtas de abastecimento alimentar, ou short food suply chain, são definidas como um sistema de inter-relações entre atores que estão diretamente engajados na produção, transformação, distribuição e consumo de alimentos (RENTING; MARSDEN; BANKS, 2017). Marsden (2004) propõe o termo "curto" para indicar a aproximação existente entre produção e consumo, tendo como propósito pensar os espaços alternativos fora dos espaços hegemônicos nos processos de produção, distribuição e consumo dos alimentos.

De acordo com Franzoni e Silva (2016), o surgimento de novas cadeias curtas de abastecimento alimentar pode ser estimulado pelo poder público por meio de políticas que visem aproximar produtores e consumidores, com a redução dos intermediários neste processo. Nesse cenário, o PNAE ganha relevância, a partir de 2009, possibilitando que agricultores familiares possam fornecer produtos para a alimentação escolar (FERNANDES; SCHNEIDER; TRICHES, 2016).

As propriedades rurais que se inserem nesses modelos de cadeias agroalimentares curtas possuem, segundo Darolt et al. (2016), em média, áreas menores que 20 hectares no total, contando com mão de obra familiar e uma gama de produtos mais diversificados quando comparado aos circuitos longos. 
Conforme Renting, Marsden e Banks (2017), uma das dimensões para descrever as relações entre produtores e consumidores nas cadeias curtas diz respeito à estrutura organizacional dessas cadeias e aos instrumentos que podem ser utilizados de modo a ampliar as relações no tempo e no espaço. Com relação a essa conceituação, as cadeias curtas de abastecimento alimentar são divididas em três tipos: as de face a face, de proximidade espacial e espacialmente estendida.

O quadro 1 apresenta uma tipologia das cadeias curtas de abastecimento alimentar e as formas de comercialização.

Quadro 1 - Tipologia de cadeias agroalimentares curtas

\begin{tabular}{|l|l|l|}
\hline \multicolumn{1}{|c|}{ Face a face } & \multicolumn{1}{c|}{ Proximidade Espacial } & \multicolumn{1}{c|}{ Espacialmente Estendida } \\
\hline 1- Tendas rurais & $\begin{array}{l}\text { 1-Grupos de lojas de produtos } \\
\text { com origem da agricultura }\end{array}$ & 1-Rótulo de certificação \\
\hline 2- Feiras de agricultores & 2-Marca regional & 2-Código de produção \\
\hline 3- O consumidor faz a colheita & 3-Cooperativas consumidoras & 3-Efeito de reputação \\
\hline 4-Venda à beira da estrada & 4-Agricultura de base comunitária & \\
\hline 5- Cestas prontas & 5-Roteiros temáticos & \\
\hline 6- Venda de porta em porta & 6-Eventos especiais e feiras & \\
\hline 7- Encomendas & $\begin{array}{l}\text { 7- Mercearias locais, restaurantes } \\
\text { e empresas de turismo }\end{array}$ & \\
\hline 8-E-commerce & 8-Varejistas especializados & \\
\hline & $\begin{array}{l}\text { 9-Abastecimento de instituições } \\
\text { (cantinas e escolas) }\end{array}$ & \\
\hline & 10-Vendas para emigrantes & \\
\hline
\end{tabular}

Fonte: Elaborado a partir de Renting, Marsden e Banks (2017) e Scarabelot e Schneider (2012).

$\mathrm{Na}$ tipologia face a face, as vendas caracterizam-se por serem realizadas diretamente do produtor ao consumidor, podendo estas ocorrer em feiras, vendas em domicílio, casas coloniais. No segundo tipo apresentado no quadro 1, o de proximidade espacial, o comércio ocorre por meio de vendas a varejistas locais, restaurantes, vendas institucionais por meio da alimentação escolar (SCARABELOT; SCHNEIDER, 2012). É esse tipo de mercado que está sendo abordado neste artigo. Esse mercado vem crescendo no município de ljuí, tendo como marco legal a Lei n. 11.947/2009. A terceira tipologia, a espacialmente estendida, refere-se a produtos certificados e de regiões que conquistam indicação geográfica.

No entendimento de Schneider e Ferrari (2015, p. 57):

[...] este movimento dos agricultores, por maior autonomia e construção de alternativas, não apenas como ações de resistência e, menos ainda, de teimosia. Na verdade, trata-se de estratégias empreendedoras que se traduzem em tentativas de capturar uma fatia maior do valor gerado nas principais cadeias de alimentos, assim como também implica na recuperação e revalorização de processos artesanais, de um "saber-fazer" vinculado ao patrimônio histórico e cultural.

As cadeias agroalimentares curtas se constituem em uma alternativa para dois problemas que os agricultores vêm enfrentando. Um deles é o aumento dos custos de produção, enquanto o outro refere-se à crescente preocupação com a segurança alimentar e a qualidade dos alimentos (SCARABELOT; SCHNEIDER, 2012). O aumento dos custos de produção diz respeito à situação em que os agricultores passam ao estarem inseridos em determinado movimento 
tecnológico, tornando-se dependentes da utilização de insumos externos, o que resulta em um aumento de custos mais elevado do que o aumento de produção, ocasionando uma diminuição em suas rendas. Em relação à crescente preocupação com a segurança alimentar, Maluf (2007) chama atenção que ela não diz respeito apenas ao acesso aos alimentos, mas também a que estes sejam saudáveis em termos nutricionais e adequados desde a ótica ambiental e cultural.

Scarabelot e Schneider (2012) destacam ainda que a reaproximação entre produtores e consumidores possibilita a valorização do comércio local, assim como a construção de relações de confiança justamente nesse espaço onde ocorrem as transações.

Como relatado em Fernandes, Schneider e Triches (2016), a produção familiar no Brasil responde por 38\% do Valor Bruto da Produção (VBP) agropecuária nacional e ocupa 77\% da mão de obra do campo. Muitos desses produtores, no entanto, não possuem acesso às redes comerciais, necessitando de intermediários para ligá-los a potenciais compradores.

Nesse cenário, produtores mais capitalizados têm maiores chances de se articularem diretamente aos mercados e, assim, de acordo com Belik (2016), conseguem ampliar sua esfera de atuação, ratificando o processo de diferenciação que existe entre as famílias de agricultores. Para que as aquisições públicas se tornem sustentáveis, Triches e Baccarin (2016) argumentam que não é somente a demanda que deve ser estruturada, mas a oferta também precisa ser explorada, criando condições para que os agricultores familiares acessem o PNAE.

\section{RESULTADOS E DISCUSSÃO}

O objetivo desta seção é descrever e analisar os dados coletados sobre o PNAE na rede municipal de ljuí e interpretá-los à luz dos conceitos de cadeias agroalimentares curtas.

\subsection{Caracterização do município de ljuí e da rede escolar municipal}

O município de ljuí está localizado na região Noroeste do Estado do Rio Grande do Sul, com área territorial de $689,37 \mathrm{~km}^{2}$ e uma população de 83.089 habitantes, conforme dados do Instituto Brasileiro de Geografia e Estatística (IBGE, 2016). Ijuí é um município de economia relativamente diversificada, com um Índice de Desenvolvimento Humano (IDHM) de 0,781, em 2010, considerado como Desenvolvimento Humano Alto (IDHM situado entre 0,700 e 0,799) (ATLAS DE DESENVOLVIMENTO HUMANO NO BRASIL, s.d.).

A Secretaria Municipal de Educação de ljuí possuía 25 escolas municipais em 2015, com 4.915 alunos matriculados em período parcial e 1.416 alunos matriculados em turno integral (INSTITUTO NACIONAL DE ESTUDOS E PESQUISAS EDUCACIONAIS ANÍSIO TEIXEIRA [INEP], 2016). Conforme as nutricionistas do município, em geral os alunos matriculados em período parcial recebem duas refeições diárias. Já os que ficam em período integral recebem quatro refeições por dia. Fazendo um cálculo aproximado do número de refeições servidas diariamente pelo município, com base no número de alunos matriculados, estima-se que aproximadamente 15.494 refeições sejam servidas por dia para os alunos da rede municipal.

Os recursos financeiros para a compra da alimentação escolar do município têm origem nos valores repassados pelo FNDE e são complementados com recursos financeiros da Prefeitura Municipal. Os recursos do FNDE devem ser investidos somente em gêneros alimentícios. Já os recursos complementados pelo município são destinados para a compra de itens como gás de cozinha, embalagens, utensílios domésticos, dentre outros itens que são necessários para que 
se materialize esse processo e que não podem ser adquiridos por meio dos valores provenientes do FNDE.

De acordo com dados do FNDE (2017), o repasse financeiro para a aquisição de gêneros alimentícios para a alimentação escolar é feito em 10 parcelas mensais, a contar do mês de fevereiro, para cobrir 200 dias letivos. O valor repassado para a União, para Estados e para os municípios, por dia letivo para cada aluno, é definido de acordo com a etapa e a modalidade de ensino, conforme o quadro 2

Quadro 2 - Valor per capita repassado pelo Fundo Nacional de Desenvolvimento da Educação (FNDE) às entidades executoras de acordo com a modalidade de ensino

\begin{tabular}{|l|c|}
\hline \multicolumn{1}{|c|}{$\quad$ Modalidade de Ensino } & $\begin{array}{c}\text { Valor per capita } \\
\text { (em R\$) }\end{array}$ \\
\hline Creches & 1,07 \\
\hline Pré-escola & 0,53 \\
\hline Escolas indígenas e quilombolas & 0,64 \\
\hline Ensino fundamental e médio & 0,36 \\
\hline Educação de Jovens e Adultos (EJA) & 0,32 \\
\hline Ensino integral & 1,07 \\
\hline Alunos do Programa Novo Mais Educação & 1,07 \\
\hline $\begin{array}{l}\text { Alunos contemplados no Programa de Fomento às Escolas de Ensino Médio em } \\
\text { tempo integral }\end{array}$ & 2,00 \\
\hline Alunos que frequentam o Atendimento Educacional Especializado no contraturno & 0,53 \\
\hline
\end{tabular}

Fonte: elaboração própria a partir de dados do FNDE (2017).

Os cardápios são elaborados por nutricionistas respeitando os hábitos alimentares locais e culturais, atendendo as necessidades nutricionais específicas conforme percentuais mínimos estabelecidos no artigo 14 da Resolução n. 26/2013 (FNDE, 2013). O município de ljuí possui duas nutricionistas concursadas, com carga horária de 37,5 horas semanais cada uma, dedicadas ao programa de alimentação escolar.

Segundo o secretário de educação, o PNAE no município passou por fases ${ }^{3}$ distintas, com características específicas. Inicialmente a alimentação escolar era vista como uma refeição que deveria "matar a fome". Eram oferecidos aos alunos produtos industrializados, como leite em pó preparado com achocolatado, chá, bolacha, dentre outros. Em cada dia da semana, era oferecido apenas um dos tipos de alimentos citados. Nesse período, as compras eram centralizadas pelo governo federal, e os alimentos eram enviados de Brasília para o município. Em um segundo momento, o município passou a oferecer um cardápio mais elaborado, incluindo refeições como: arroz com galinha, feijão, carne. Nos dias em que eram oferecidas frutas, não era possível oferecer outro alimento, devido aos recursos disponíveis não serem suficientes. O Secretário de Educação relata que, nesse período, o Programa iniciou um processo visando qualificar a alimentação escolar. Nessa etapa, o município já contava com o acompanhamento de nutricionistas, mas ainda não existiam condições de se fazer um cardápio mais elaborado, que pudesse atender as necessidades nutricionais diárias dos alunos.

\footnotetext{
${ }^{3}$ Os entrevistados se referiram ao histórico do programa de alimentação como sendo dividido em fases, no entanto não souberam delimitar as datas com exatidão, preferindo utilizar o termo "períodos".
} 
A implementação da Lei n. 11.947/2009 representou um marco legal para o Programa de alimentação escolar, possibilitando qualificar as refeições que eram servidas nas escolas e respeitando os hábitos alimentares e a cultura locais. Segundo relato da nutricionista do programa, no município já existia uma pretensão em adquirir produtos dos agricultores locais. No entanto a legislação era rígida, pois as compras eram realizadas via licitação, pelo menor preço (Lei n. 8666/1993) e, dessa forma, excluía a possibilidade de os agricultores familiares locais dela participarem. A partir de 2009, esse cenário mudou e, com a nova lei, foi possível colocar em prática os novos mecanismos de aquisição dos alimentos da agricultura familiar, utilizando-se de chamadas públicas 4 .

No município estudado, de acordo com as informações dos entrevistados, houve uma mobilização entre os setores envolvidos com o processo de aquisição dos produtos para a alimentação escolar, a saber: Secretário de Educação, as nutricionistas do programa, funcionários responsáveis por elaborar as chamadas públicas, agentes da Secretaria de Desenvolvimento Rural e produtores rurais da região, dentre outros. Foram realizadas reuniões entre os referidos setores para organizar os agricultores em grupos que pudessem dar conta da produção que as escolas necessitassem. Dessa forma, teve início a construção do mercado institucional no município.

Esse tipo de mercado institucional gerado pela alimentação escolar enquadra-se na tipologia de "proximidade espacial", descrita por Scarabelot e Schneider (2012) e por Renting, Marsden e Banks (2017). Cadeias curtas próximas podem incluir atores intermediários de cadeia agroalimentar, os quais têm como intuito garantir a procedência dos produtos que estão sendo comercializados (RENTING; MARSDEN; BANKS, 2017).

Buscando organizar os agricultores familiares de forma que eles tivessem condições de atender a demanda de alimentos das escolas municipais, em um primeiro momento eles foram divididos em grupos para o fornecimento de hortaliças. Cada grupo foi dividido em um determinado número de produtores (em média 3), os quais ficavam responsáveis por entregar os mesmos produtos nos prazos previamente estipulados. Após a conclusão da primeira etapa, iniciou-se a aquisição de produtos de origem animal e das agroindústrias familiares da região.

A partir do âmbito local e da aproximação entre vendedores e compradores, forma-se um mercado emergente, característico dos circuitos curtos de comercialização (SCHNEIDER; FERRARI, 2015). Em ljuí, esse mercado formou-se a partir da implementação da legislação que possibilitou a aquisição dos produtos da agricultura familiar, permitindo que consumidores e fornecedores se aproximassem e criassem os laços que permitem a comercialização de produtos de qualidade para a alimentação escolar da rede municipal.

\subsection{A alimentação escolar na rede municipal de educação de ljuí}

No quadro 3, pode-se observar os valores repassados pelo FNDE para o município de ljuí, a partir do ano de $2011^{5}$, destinados à aquisição da alimentação escolar, bem como o percentual desses valores que foram destinados à agricultura familiar.

\footnotetext{
${ }^{4}$ Nas compras da agricultura familiar para o PNAE é permitida a dispensa do processo licitatório tradicional (Lei n. 8666/1993) e as compras podem ser realizadas por meio do instrumento de compra denominado "chamada pública", desde que atendidos os preceitos constitucionais de legalidade, impessoalidade, moralidade, publicidade e eficiência, e os preços estejam em conformidade com os preços médios praticados no mercado local (AMARAL, 2016).

${ }^{5}$ A Coordenadoria de Nutrição Escolar de ljuí só liberou os valores repassados pelo FNDE para a alimentação escolar a partir de 2011.
} 
Quadro 3 - Valores repassados pelo Fundo Nacional de Desenvolvimento da Educação (FNDE) para a alimentação escolar na rede municipal de ljuí e valores - absolutos e relativos destinados à aquisição de produtos da Agricultura Familiar

\begin{tabular}{|c|c|c|c|}
\hline Ano & $\begin{array}{c}\text { Valor transferido pelo } \\
\text { FNDE (em R\$) }\end{array}$ & Aquisição da agricultura familiar & $\begin{array}{c}\text { Porcentagem da } \\
\text { agricultura familiar }\end{array}$ \\
\hline 2011 & $485.400,00$ & $187.297,36$ & $38,59 \%$ \\
\hline 2012 & $617.520,00$ & $226.397,99$ & $36,66 \%$ \\
\hline 2013 & $768.376,00$ & $261.997,25$ & $34,10 \%$ \\
\hline 2014 & $639.546,00$ & $304.059,62$ & $47,54 \%$ \\
\hline 2015 & $771.180,00$ & $485.992,72$ & $63,00 \%$ \\
\hline
\end{tabular}

Fonte: Elaboração própria a partir dos dados da pesquisa documental e de campo.

Conforme está evidenciado no quadro 3, desde 2011 o percentual destinado às aquisições da agricultura familiar tem sido superior ao mínimo exigido em lei, com tendência de elevação da participação de produtos fornecidos por agricultores familiares locais. Os atores sociais entrevistados relataram que existe um esforço por parte da Secretaria de Educação para, além do cumprimento da legislação, comprarem alimentos da agricultura familiar de forma que a prática beneficie a todos os envolvidos no processo: alunos, agricultores e economia local, dentre outros.

A realidade identificada no município de ljuí vai ao encontro do conceito de cadeias curtas utilizado por Schneider e Gazolla (2017). Para esses autores, as cadeias agroalimentares curtas de abastecimento podem ser compreendidas enquanto um movimento de busca pelos atores sociais envolvidos em uma cadeia de valor para a construção de novas formas de relacionamento entre produtores e consumidores buscando resgatar a procedência e a identidade dos produtos. Os autores evidenciam que essas relações não estão pautadas apenas em preceitos como o preço, mas levam em consideração "valores sociais, princípios e significados simbólicos, culturais, éticos e ambientais" (SCHNEIDER; GAZOLLA, 2017, p. 12).

Percebe-se que os agentes envolvidos na aquisição da alimentação escolar do município de ljuí vêm se mobilizando em favor da inserção dos alimentos provenientes da agricultura familiar, conforme o relato dos diferentes entrevistados:

No ano em que saiu a lei permitindo a compra de produtos da agricultura familiar o município já fez a primeira compra, procurando mobilizar os agricultores, mesmo neste primeiro ano não sendo obrigatório o cumprimento da lei. A mudança na qualidade dos alimentos foi algo extraordinário. (NUTRICIONISTA DO PNAE EM IJUÍ).

Atualmente o cenário está consolidado, procurando, no mínimo, atender a exigência de adquirir $30 \%$ dos alimentos para alimentação escolar em produtos da agricultura familiar, $e$, se possivel, ultrapassar este percentual. O município vem fazendo esforços para cumprir a lei e, sempre que possivel, superar o percentual mínimo exigido. A imposição da Lei no 11.947/2009 trouxe "qualificação" para o PNAE em ljuí, trazendo alimentos mais saudáveis e com origem da própria região. (SECRETÁRIO MUNICIPAL DE EDUCAÇÃO DE IJUÍ).

A partir da implementação da Lei n. 11.947/2009, ocorreu um processo de mobilização entre os diferentes agentes envolvidos, conforme já citado. Foram realizadas reuniões prévias entre os diferentes representantes de cada um dos setores envolvidos com o intuito de organizar os agricultores para que os mesmos pudessem produzir os alimentos que as escolas precisariam. Além disso, o setor de compras instruiu os agricultores sobre como participar das chamadas públicas. 
A operacionalização do PNAE nas escolas municipais de ljuí confirma que, como se refere Triches (2015), por meio de uma política pública, o governo federal possibilitou que as compras públicas inserissem agricultores familiares locais aos mercados institucionais de alimentação escolar. Ainda existem entraves operacionais, estruturais, políticos e econômicos que devem ser enfrentados na construção e gerenciamento desse mercado. Afinal, cabe ressaltar que a ação e a relação entre os atores sociais envolvidos no processo de aquisição pública é um dos aspectos fundamentais para que a legislação tenha ou não efetividade.

A Secretaria Municipal de Educação de ljuí possui um local para o recebimento dos gêneros alimentícios que serão distribuídos nas escolas através de um veículo equipado para transportar alimentos in natura e perecíveis. Os alimentos perecíveis são distribuídos semanalmente, e os alimentos não perecíveis, mensalmente.

\subsection{A implementação da Lei n. 11.947/2009 e seu funcionamento na rede escolar municipal de ljuí}

O município de ljuí possui aproximadamente 18 agricultores familiares da região habilitados como fornecedores individuais que fornecem mais de 40 produtos para a alimentação escolar (IJUÍ, s.d.). Para se habilitarem como fornecedores individuais de produtos ao PNAE, esses agricultores devem apresentar os seguintes comprovantes: prova de inscrição do Cadastro de Pessoas Físicas, extrato da Declaração de Aptidão ao Programa Nacional de Fortalecimento da Agricultura Familiar do agricultor participante, emitido nos últimos 60 dias e declaração de que os alimentos a serem entregues são de produção própria (AMARAL, 2016).

Os circuitos de produtos provenientes das agroindústrias e da agricultura familiar são caracterizados pelas relações de proximidade entre produtor e consumidor, em que a confiança no produto remete ao local de origem deste, relações essas que são construídas socialmente, como destacado por Scarabelot e Schneider (2012). No caso de ljuí, segundo a nutricionista entrevistada, os produtores mais próximos estão localizados a $6 \mathrm{~km}$ de distância da cidade, o que possibilita a aquisição de alimentos, em especial frutas e verduras, mais frescos, mais ricos em nutrientes e mais saudáveis, quando comparados a alimentos que vêm de regiões mais distantes, pois as perdas de qualidade decorrentes do transporte e do tempo entre a colheita e o consumo são menores.

De acordo com a fala que se reproduz de forma semelhante nos três entrevistados, em especial junto ao Secretário de Educação e à nutricionista, destaca-se a existência de parcerias que facilitam a gestão do programa no município, em especial entre a Secretaria de Educação e os produtores que se empenham em cumprir os acordos e prazos estabelecidos.

Segundo a nutricionista, estar "face a face" com o produtor ajuda a criar relações de confiança, em que se passa a conhecer a origem do alimento que será oferecido aos alunos. Nesse sentido, Balestro (2017) destaca que, nas cadeias curtas de produção, o relacionamento de mercado com os consumidores em geral é acompanhado de elementos estabelecidos em relações baseadas na confiança interpessoal ou então na confiança nas instituições. No caso do município estudado, percebe-se que foram construídas relações de confiança entre os agricultores e as nutricionistas que organizam as compras, possibilitando o alcance de bons resultados.

As informações apreendidas nas entrevistas e observações diretas igualmente convergem com Maluf (2007) quando afirma que, nas cadeias agroalimentares curtas, a possibilidade de 
articular produtores locais e consumidores de alimentos traz benefícios para ambos os envolvidos. Por um lado, reduz os gastos com transportes e, por outro, facilita a oferta de alimentos de qualidade e hábitos de consumo mais diversificados. Nesse contexto, o Estado possui um papel importante no sentido de criar programas que estimulem a interação entre esses atores sociais e que também estimulem a economia local das regiões envolvidas, objetivos que nortearam as alterações no PNAE a partir da Lei n. 11.947/2009.

Quando questionados sobre quais as dificuldades encontradas na gestão do PNAE, os entrevistados destacaram que os recursos são escassos e que é necessário fazer "milagre" para dar conta de adquirir produtos de qualidade. Dessa forma, para a elaboração dos cardápios é levado em conta a sazonalidade dos alimentos, os preços, os produtos que estão em falta ou com preços mais elevados que o normal.

Os funcionários que manipulam os alimentos precisam estar em constantes atualizações para que saibam como preparar as refeições sem que ocorram desperdícios, sendo este um desafio diário, conforme relato da nutricionista. Somente comprar alimentos saudáveis não garante alimentação saudável e de qualidade, relatou o Secretário de Educação.

Segundo o Secretário, a atuação das nutricionistas é fundamental para que o programa funcione. No caso de ljuí, elas estão vinculadas à Secretaria da Saúde e não à pasta da Educação. De acordo com o FNDE (2013), a atuação do profissional nutricionista é fundamental para a execução do PNAE, pois cabe-Ihe a tarefa de realizar atividades de planejamento, coordenação, direção, supervisão e avaliação de todas as ações de alimentação e nutrição no âmbito da alimentação escolar.

O controle social do PNAE é realizado pelo Conselho de Alimentação Escolar (CAE), um órgão deliberativo, fiscalizador e de assessoramento do PNAE (FNDE, s.d.). A constituição desse órgão, segundo o secretário de educação de ljuí, é exigência para que o FNDE repasse os recursos financeiros para aquisição da alimentação escolar. No caso das cadeias agroalimentares curtas, que envolve a participação de fornecedores individuais e grupos informais no suprimento de produtos ao PNAE, as tarefas de fiscalização e assessoramento do CAE são facilitadas pela proximidade entre produtores (agricultores familiares) e consumidores (estudantes) e gestores do programa (servidores públicos), corroborando os estudos de Triches e Schneider (2010).

Quanto à composição do CAE no município de ljuí, esse órgão é constituído por um presidente (que também representa a sociedade civil), mais um representante da sociedade civil, um do poder executivo, dois de pais de alunos e dois de professores.

De acordo com o secretário de educação do município, o CAE realiza reuniões regulares e seus membros fazem visitas às escolas e aos produtores rurais, fiscalizando as condições de produção dos alimentos, bem como as condições em que estes são preparados e oferecidos aos alunos. O CAE fiscaliza os cardápios elaborados pelas nutricionistas e as atividades desenvolvidas pelo programa, tais como avaliação nutricional e aceitabilidade dos alimentos pelos alunos. É também o CAE que elabora os relatórios e pareceres que são enviados para o FNDE. Tais resultados reforçam as evidências de Triches e Baccarin (2016) de que a instituição dos CAEs em nível municipal contribuiu para que houvesse melhorias substanciais na qualidade da alimentação escolar.

Em relação à existência de atividades de Educação Alimentar e Nutricional (EAN) na escola selecionada para a pesquisa, foi relatado que a escola possui horta escolar, e os produtos que dela provêm complementam a alimentação, como saladas e temperos, mas essas atividades dependem do clima. Existe uma professora que cuida da horta na escola e também é responsá- 
vel pelo projeto de Educação Ambiental. Os alunos do segundo, quarto e quinto ano do ensino fundamental auxiliam no cuidado da horta e também frequentam aulas de jardinagem.

Os alimentos oferecidos pela escola possuem boa aceitabilidade por parte dos alunos, os quais participam em sua maioria das refeições que são oferecidas. Na escola pesquisada, a diretora relatou que os alunos, de maneira geral, não apresentam sinais de carência alimentar. No entanto a alimentação é muito valorizada, e esse momento é muito esperado e celebrado, como um ritual de confraternização.

Quando questionados sobre a influência da alimentação escolar para a permanência ou retorno dos alunos nas escolas do município, observou-se que os entrevistados possuíam opiniões diferentes. De acordo com o Secretário de Educação:

A alimentação faz parte da vida escolar. Com fome é mais difícil aprender. Ainda existem realidades em escolas da rede municipal onde a alimentação é um fator que faz com que o aluno frequente a escola. Alguns alunos frequentam a escola para "matar a fome", mas não se constitui a maioria. Ainda não se consegue pensar em manter alunos nas escolas do município sem oferecer a alimentação. Percebe-se a participação da maioria dos alunos na hora da alimentação escolar. (SECRETÁRIO MUNICIPAL DE EDUCAÇÃO DE IJUÍ).

Já a nutricionista do programa relata que não consegue enxergar a alimentação escolar como determinante para a permanência dos alunos na escola. Segundo ela, na última década, principalmente em função dos programas assistenciais oferecidos pelo governo brasileiro para a população em situação de vulnerabilidade, a realidade de extrema carência alimentar nas escolas do município vem diminuindo, mas ela ainda existe, e a alimentação escolar tem um papel fundamental para enfrentar esses problemas.

Por sua vez, a escola pesquisada não compõe o grupo de escolas onde a maioria dos alunos se encontra em extrema pobreza, com privações alimentares. Nesse contexto, a diretora da escola enxerga a alimentação escolar como complementar para a permanência do aluno na escola, e não como determinante.

\section{CONSIDERAÇÕES FINAIS}

Considera-se que uma alimentação adequada e hábitos alimentares saudáveis desde a infância são fundamentais para o desenvolvimento do ser humano. Além disso, a alimentação é um direito de todos, e o Estado tem um papel importante para suprir essas necessidades da população por meio de políticas públicas.

As falas dos diferentes agentes envolvidos no processo de aquisição da alimentação escolar em ljuí apontam impactos positivos para todos os participantes. Do produtor, que fornece o alimento e aufere uma renda que garante seu sustento ou complementa seus rendimentos, até o aluno que se beneficia com uma refeição saudável e com procedência de origem oferecida pela escola.

No município, houve esforço para que fosse possível adquirir alimentos de produtores locais junto ao PNAE. O aceite desse procedimento é considerado uma conquista para os gestores do programa em ljuí. Todos os agentes envolvidos buscaram fazer com que fosse possível alcançar os percentuais exigidos na lei. Essa experiência vem se consolidando e ampliando as parcerias com os produtores da região para que seja possível aumentar, a cada ano, o volume dos produtos por eles produzidos. Essas ações trazem benefícios para todos os atores envolvidos nesse processo: gestores, alunos, agricultores familiares e economia local. 
Desde a implementação da Lei n. 11.947/2009, foi possível melhorar significativamente a qualidade da alimentação oferecida nas escolas municipais de ljuí. Houve a inclusão de alimentos produzidos localmente, respeitando os hábitos alimentares regionais e trazendo impactos positivos na aceitabilidade das refeições pelos alunos. Além disso, percebeu-se também, pelas entrevistas, que os impactos vêm sendo positivos igualmente para os agricultores da região.

O exemplo de ljuí, objeto deste estudo, evidenciou a importância da interação e comprometimento entre os gestores do PNAE e, também, entre estes e os fornecedores. Isso é fundamental para se compreender as conquistas que esse programa vem alcançando no município ao longo dos anos.

O número de entrevistados pode ser considerado um limite do estudo, em parte compensado pelo nível de envolvimento deles com o objeto de estudo. Para estudos futuros, sugere-se a necessidade de se aprofundar pesquisas junto aos empreendimentos e organizações da agricultura familiar locais, a fim de se compreender sua dinâmica e sua forma de inserção nesse mercado de alimentação escolar.

\section{REFERÊNCIAS}

AMARAL, Volmir R. do. Potencialidades e limites da política de alimentação escolar na promoção da agricultura familiar. 2016. 102f. Dissertação (Mestrado em Desenvolvimento) - Universidade Regional do Noroeste do Estado do Rio Grande do Sul, ljuí, 2016.

ATLAS DE DESENVOLVIMENTO HUMANO NO BRASIL. Perfil. Ijuí, RS. [s.d.]. Disponível em: http://www. atlasbrasil.org.br/2013/pt/perfil_m/ijui_rs. Acesso em: 19 jan. 2017.

BALESTRO, Moisés V. Contribuições metodológicas para análise das cadeias curtas de produção: os ganhos da comparação e da causalidade. In: SCHNEIDER, Sergio; GAZOLLA, Marcio (Org.). Cadeias curtas e redes agroalimentares alternativas. Porto Alegre, RS: UFRGS, 2017. p. 147-72.

BASSO, David. Fundamentos teóricos e procedimentos metodológicos para a análise de processos reais de desenvolvimento. In: SIEDENBERG, Dieter R. (Org.). Desenvolvimento sob múltiplos olhares. Ijuí, RS: Unijuí, 2012. p. 101-37.

BELIK, Walter. Agricultura familiar, políticas públicas e os novos mercados. In: TEO, Carla Rosane P. A.; TRICHES, Rozane Marcia (Org.). Alimentação escolar: construindo interfaces entre saúde, educação e desenvolvimento. Chapecó, SC: Unochapecó, 2016. p. 65-88.

BRASIL. Lei n. 11.947, de 16 de junho de 2009. Dispõe sobre o atendimento da alimentação escolar e do Programa Dinheiro Direto na Escola aos alunos da educação básica (....). Diário Oficial da União, Brasília, DF, 16 jun. 2009.

BRASIL. Lei n. 8.666, de 21 de junho de 1993. Regulamenta o art. 37, inciso XXI, da Constituição Federal, institui normas para licitações e contratos da Administração Pública e dá outras providências. Disponível em: http://www.planalto.gov.br/ccivil_03/leis//8666cons.htm. Acesso em: 22 jan. 2017.

DAROLT, Moacir Roberto et al. Redes alimentares alternativas e novas relações produção-consumo na França e no Brasil. Ambiente \& Sociedade, São Paulo, v. XIX, n. 2, p. 1-22, abr./jun. 2016.

FERNANDES, Patrícia F.; SCHNEIDER, Sérgio; TRICHES, Rozane Marcia. Identificação da oferta de produtos da agricultura familiar e da demanda pelo Programa de Alimentação Escolar das escolas estaduais do Rio Grande do Sul. In: TEO, Carla Rosane P. A.; TRICHES, Rozane Marcia (Org.). Alimentação escolar: construindo interfaces entre saúde, educação e desenvolvimento. Chapecó, SC: Unochapecó, 2016. p. 169-99. 
FRANZONI, Gabriel B.; SILVA, Tania N. Inovação Social e Tecnologia Social: o caso da cadeia curta de agricultores familiares e a alimentação escolar em Porto Alegre/RS. Desenvolvimento em Questão, ljuí, RS, v. 14, n. 37, p. 358-91, edição especial 2016.

FROEHLICH, Elisângela. A capacidade de "Fazer Diferente": os condicionantes legais e as estratégias de governança na implementação do programa de alimentação escolar em Dois Irmãos e Tapes (RS). 2010. 152f. Dissertação (Mestrado em Desenvolvimento Rural) - Universidade Federal do Rio Grande do Sul, Porto Alegre, 2010.

FUNDO NACIONAL DE DESENVOLVIMENTO DA EDUCAÇÃO (FNDE). Resolução CD/FNDE $n$. 1, de 8 de fevereiro de 2017. Disponível em: https://www.fnde.gov.br/acesso-a-informacao/institucional/legislacao/ item/10900-resolu\%C3\%A7\%C3\%A3o-cd-fnde-mec-n\%C2\%BA-1,-de-8-de-fevereiro-de-2017. Acesso em: 17 mar. 2017.

FUNDO NACIONAL DE DESENVOLVIMENTO DA EDUCAÇÃO (FNDE). Resolução CD/FNDE . 26 de 17 de junho de 2013. Dispõe sobre o atendimento da alimentação escolar aos alunos da educação básica no âmbito do PNAE. Diário Oficial [da] União, Brasília, DF, 14 jun. 2013.

FUNDO NACIONAL DE DESENVOLVIMENTO DA EDUCAÇÃO (FNDE). Programa Nacional de Alimentação Escolar. Histórico. [s.d.]. Disponível em: http://www.fnde.gov.br/programas/programas-suplementares/ pnae-sobre-o-programa/pnae-historico. Acesso em: 17 nov. 2016.

GIL, Antônio Carlos. Métodos e técnicas de pesquisa social. São Paulo: Atlas, 2016.

IJUÍ. Desenvolvimento rural: merenda escolar. [s.d.]. Disponível em: http://www.ijui.rs.gov.br/secretarias/ desenvolvimento_rural/merenda_escolar. Acesso em: 23 jan. 2017.

INSTITUTO BRASILEIRO DE GEOGRAFIA E ESTATÍSTICA (IBGE). IBGE cidades. Disponível em: http://www. cidades.ibge.gov.br/xtras/perfil.php?lang=\&codmun=431020/. Acesso em: 3 dez. 2016.

INSTITUTO NACIONAL DE ESTUDOS E PESQUISAS EDUCACIONAIS ANÍSIO TEIXEIRA (INEP). Sinopse Estatística da Educação Básica 2015. Brasília: Inep, 2016. Disponível em: http://inep.gov.br/sinopsesestatisticas-da-educacao-basica. Acesso em: 23 jan. 2017.

MALUF, Renato Sérgio Jamil. Segurança alimentar e nutricional. Petrópolis, RJ: Vozes, 2007.

MARSDEN, Terry. Theorising food quality: some key issues in understanding its competitive production and regulation. In: HARVEY, Mark; MCMEEKIN, Andrew; WARDE, Alan. (Ed.). Qualities of food. New York: Palgrave, 2004. p. 129-55.

MORGAN, Kevin; SONNINO, Roberta. Repensando a alimentação escolar: o poder do prato público. In: WORLDWATCH INSTITUTE. Estado do mundo: transformando culturas- do consumismo à sustentabilidade. Bahia: Ed. UMA, 2010.

ORGANIZACIÓN DE LÁS NACIONES UNIDAS PARA LA AGRICULTURA Y LA ALIMENTACIÓN (FAO). Programas de alimentación escolar y compras da agricultura familiar campesina en los programas sociales de asistencia alimentaria: taller técnico regional. Manágua: [s.n.], 2011.

RENTING, Henk; MARSDEN, Terry; BANKS, Jo. Compreendendo as redes alimentares alternativas: o papel das cadeias curtas de abastecimento de alimentos no desenvolvimento rural. In: SCHNEIDER, Sergio; GAZOLLA, Marcio (Org). Cadeias curtas e redes agroalimentares alternativas. Porto Alegre: UFRGS, 2017. p. 27-51. 
SCARABELOT, Maristela; SCHNEIDER, Sergio. As cadeias agroalimentares curtas e desenvolvimento local - um estudo de caso no município de Nova Veneza/SC. Faz Ciência, Francisco Beltrão, PR, v. 14, n. 19, jan./ jun.. 2012. p. 101-30.

SCHNEIDER, Sergio; FERRARI, Dilvan Luiz. Cadeias curtas, cooperação e produtos de qualidade na agricultura familiar - o processo de relocalização da produção agroalimentar em Santa Catarina. Organizações Rurais \& Agroindustriais, Lavras, MG, v. 17, p. 56-71, n. 1, jan./mar. 2015.

SCHNEIDER, Sergio; GAZOLLA, Marcio. Cadeias curtas e redes agroalimentares alternativas. In: SCHNEIDER, Sergio; GAZOLLA, Marcio (Org.). Cadeias curtas e redes agroalimentares alternativas. Porto Alegre, RS: UFRGS, 2017. p. 9-24.

SILVA NETO, Benedito. Análise-Diagnóstico de Sistemas Agrários: uma interpretação baseada na Teoria da Complexidade e no Realismo Crítico. Desenvolvimento em Questão, Ijuí, RS, v. 5, n. 9, p. 33-58, jan./ jun. 2007.

TRICHES, Rozane Marcia. Repensando o mercado da alimentação escolar: novas institucionalidades para o meio rural. In: GRISA, Catia; SCHNEIDER, Sergio (Org.). Políticas públicas de desenvolvimento rural no Brasil. Porto Alegre: UFRGS, 2015. p. 161-200.

TRICHES, Rozane Marcia; SCHNEIDER, Sergio. Alimentação escolar e agricultura familiar: reconectando o consumo à produção. Saúde e Sociedade, São Paulo, v. 19, n. 4, p. 933-45, out./dez. 2010.

TRICHES, Rozane Marcia; BACCARIN, José Giacomo. Interações entre alimentação escolar e agricultura familiar para o desenvolvimento local. In: TEO, Carla Rosane P. A.; TRICHES, Rozane Marcia (Org.). Alimentação escolar: construindo interfaces entre saúde, educação e desenvolvimento. Chapecó, SC: Unochapecó, 2016. p. 89-109.

\section{Sobre os autores:}

Indaia Dias Lopes: Doutoranda em História pela Universidade de Passo Fundo (PPGH/ UPF), Bolsista Prosuc/Capes. Mestra em Desenvolvimento Regional pela Universidade Regional do Noroeste do Estado do Rio Grande do Sul (PPGDR/Unijuí). Economista pela Universidade Federal de Santa Maria (UFSM). E-mail: indaia_lopes@yahoo.com.br, Orcid: http://orcid.org/0000-0003-2966-8461

David Basso: Doutor em Desenvolvimento, Agricultura e Sociedade pela Universidade Federal Rural do Rio de Janeiro (UFRRJ). Docente permanente do Programa de Pós-Graduação (mestrado e doutorado) em Desenvolvimento Regional (PPGDES) na Unijuí. Editor da revista Desenvolvimento em Questão (ISSN 2237-6453). Professor titular nível IV da Unijuí. E-mail: davidbasso@unijui.edu.br, Orcid: http://orcid.org/0000-0002-4610-9269

Argemiro Luís Brum: Doutor em Economia Internacional - Ecole des Hautes Etudes en Sciences Sociales. Mestre em Economia Agrícola - Institut Agronomique Méditerranéen de Montpellier. Graduado em Administração de Empresas e em Tecnólogo em Cooperativismo pela Unijuí. Professor titular da Unijuí, coordenador da Central Internacional de Análises Econômicas e de Estudos de Mercado Agropecuário (CEEMA/DACEC/UNIJUI), membro do Colegiado de Coordenação do Mestrado em Desenvolvimento Regional (UNIJUI). E-mail: argelbrum@unijui.edu.br, Orcid: http://orcid.org/0000-0002-8763-9514 
